\title{
Spatial ecology of little egret (Egretta garzetta) in Hong Kong uncovers preference for commercial fishponds
}

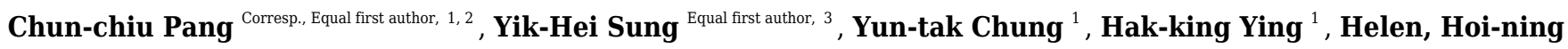 \\ Fong ${ }^{1}$, Yat-tung Yu ${ }^{1}$ \\ 1 The Hong Kong Bird Watching Society, Hong Kong SAR, China \\ 2 School of Biological Sciences, The University of Hong Kong, Hong Kong SAR, China \\ 3 Science Unit, Lingnan University, Hong Kong SAR, China \\ Corresponding Author: Chun-chiu Pang \\ Email address: pchunchiu@hkbws.org.hk
}

Many natural wetlands have been converted to human-influenced wetlands. In some instances, human-influenced wetlands could provide complementary habitats for waterbirds, compensating for the loss of natural wetlands. Inner Deep Bay in Hong Kong is composed of both natural and human-influenced wetlands and is under immense development pressure. From an ecology perspective, we need to understand if different wetland types play the same ecological role. To achieve this, we tracked nine little egrets (Egretta garzetta) using GPS loggers for 14 months to study their spatial ecology, home range, movement and habitat use. We found that over $88 \%$ of the home range of all individuals comprised of wetlands (commercial fishponds, mangrove, gei wai, channel, and intertidal mudflat). Among these wetland types, nearly all (seven of nine) individuals preferred commercial fishponds over other habitats in all seasons. Little egrets exhibited seasonal movement and habitat use among seasons, with largest home range, greatest movement, and most frequent visits to commercial fishponds in winter compared to spring and autumn. Our results highlight the significant role of commercial fishponds, providing a feeding ground for little egrets. However, other wetland types cannot be ignored, as they were also used considerably. These findings underscore the importance of maintaining a diversity of wetland types as alternative foraging and breeding habitats. 
1 Title

2 Spatial ecology of little egret (Egretta garzetta) in Hong Kong uncovers preference for

3 commercial fishponds

4

5 Pang, Chun-chiu ${ }^{12}$; Sung, Yik-Hei ${ }^{3}$; Chung Yun-tak ${ }^{1}$; Ying Hak-king ${ }^{1}$; Helen, Fong Hoi-ning ${ }^{1}$;

$6 \mathrm{Yu}$, Yat-tung ${ }^{1}$

7

$8{ }^{1}$ The Hong Kong Bird Watching Society, Hong Kong SAR, China

$9{ }^{2}$ School of Biological Sciences, The University of Hong Kong, Hong Kong SAR, China

$10{ }^{3}$ Science Unit, Lingnan University, Hong Kong SAR, China

11

12

Corresponding author

14

Pang, Chun-chiu

15

pchunchiu@hkbws.org.hk

16

17

\section{ABSTRACT}

Many natural wetlands have been converted to human-influenced wetlands. In some instances, human-influenced wetlands could provide complementary habitats for waterbirds, compensating for the loss of natural wetlands. Inner Deep Bay in Hong Kong is composed of both natural and human-influenced wetlands and is under immense development pressure. From an ecology perspective, we need to understand if different wetland types play the same ecological role. To achieve this, we tracked nine little egrets (Egretta garzetta) using GPS loggers for 14 months to study their spatial ecology, home range, movement and habitat use. We found that over $88 \%$ of the home range of all individuals comprised of wetlands (commercial fishponds, mangrove, gei wai, channel, and intertidal mudflat). Among these wetland types, nearly all (seven of nine) individuals preferred commercial fishponds over other habitats in all seasons. Little egrets exhibited seasonal movement and habitat use among seasons, with largest home range, greatest movement, and most frequent visits to commercial fishponds in winter compared to spring and autumn. Our results highlight the significant role of commercial fishponds, providing a feeding ground for little egrets. However, other wetland types cannot be ignored, as they were also used considerably. These findings underscore the importance of maintaining a diversity of wetland types as alternative foraging and breeding habitats.

\section{Keywords}


37 Bird, GPS tracking, habitat use, home range, sustainable land-use management, wetland conservation

\section{INTRODUCTION}

In recent centuries, over half of natural wetlands have been lost, and a large proportion have been converted to human-influenced wetlands (Davidson 2014; Gong et al. 2010). Such conversion is typically considered detrimental to biodiversity, since many waterbirds rely on natural wetlands as foraging and breeding grounds (Bellio et al. 2009; Ma et al. 2004; Sebastián-González \& Green 2016). However, some studies have found that human-influenced wetlands could provide alternative, complementary habitats for some species (Fidorra et al. 2016; Giosa et al. 2018; Kloskowski et al. 2009; Li et al. 2013; Márquez-Ferrando et al. 2014). In some cases, the transformation from natural to human-influenced wetlands has increased bird diversity due to enhanced habitat heterogeneity (Murillo-Pacheco et al. 2018). Also, aquaculture commercial fishponds can provide essential feeding grounds for waterbirds (Navedo et al. 2015; Ramirez et al. 2012). A high number of birds are attracted when commercial fishponds are periodically drained for harvest; the draining practice opens up opportunities for waterbirds, easing the capture of concentrated prey as water depth is reduced (Navedo et al. 2015). To understand the ecological role of different wetland types (natural and human-influenced), new studies are needed comparing the suitability of different wetlands to waterbirds, particularly in parts of the world where diverse waterbird communities are being threatened by destruction of wetlands.

The Inner Deep Bay, a Ramsar site in Hong Kong, is an important site for migratory waterbirds, housing over 40,000 birds each winter, including threatened species (Hong Kong Bird Watching Society 2018). The area is a complex landscape with a variety of wetlands (e.g. commercial fishponds, mangrove, and intertidal mudflats) and urban settlements. This area has been under high pressure for housing development (Morton 2016; Young 1998) and wetlands have declined by 53\% between 1986 and 2007 (Ren et al. 2010). Among wetland types, commercial fishponds are particularly vulnerable because most are located outside the designated Ramsar site and have limited legal protection against development. Data on the habitat use of waterbirds in the area can be used to evaluate the ecological role of different wetland types, thereby providing a basis for wetland conservation and informing land-use management.

Recently, with the technological advancement of tracking devices, tracking studies have been widely used to study the spatial ecology of birds. Advanced tracking methods (e.g., ARGOS or GPS tracking) gather real-time data with accurate location information that traditional bird surveys cannot provide. The resolution of these data can account for variation in movement and 
73 habitat use (Koczur et al. 2018; Takano \& Haig 2004), thereby enhancing our ability to evaluate

74 the habitat quality for birds and yield data to guide habitat management and conservation (e.g.

75 El-Hacen et al. 2013; Mitchell et al. 2016).

76

77 In this study, we used GPS tracking to study the spatial ecology of little egrets (Egretta garzetta)

78 in the Inner Deep Bay, Hong Kong. In the area, little egrets are present throughout the year with 79 a population peaks in winter (1000-2000 individuals in January) (Carey et al. 2001). Since they

80 inhabit a diversity of wetlands, little egrets provide an ideal study system to compare the 81 ecological role of different wetland types (Martínez-Vilalta et al. 2019; Young 1998). Further,

82 although the little egret is one of the most widespread ardeid species worldwide (Martínez-

83 Vilalta et al. 2019), there has yet been any tracking study investigating its spatial ecology. The

84 main goal of this study was to provide new knowledge on little egret spatial ecology. The 85 specific objectives were to determine home range sizes, movements and habitat use of little 86 egrets. More specifically, we aimed to evaluate whether little egrets exhibit a preference for 87 certain habitats. Since draining of commercial fishponds - usually October-May in the Inner 88 Deep Bay (Young 1998) - drives to reduced water depth and therefore prey concentration 89 (Navedo et al. 2015), we expected this seasonal draining to attract little egrets in such period of 90 the year, thus having a major influence on the spatial ecology of the species. These data may 91 contribute to the conservation of waterbirds in Hong Kong and to guide habitat management in 92 landscape mosaics consisting of natural and human-influenced wetlands worldwide. 93

\section{MATERIALS AND METHODS}

\section{Study area}

96 This study was carried out in the Inner Deep Bay of the Hong Kong Special Administrative 97 Region, China $\left(22^{\circ} 29^{\prime} \mathrm{N} 114^{\circ} 02^{\prime} \mathrm{E}\right)$. The area consists of a natural, shallow estuarine bay with 98 extensive intertidal mudflats connected to mangroves and human-influenced wetlands, including 99 gei wais (tidal shrimp ponds), drainage channels and commercial fishponds. The commercial 100 fishponds form a continuous wetland habitat of approximately 460 ha. Individual fishponds are generally 1-3 hectares in size, and contain polycultures of commercial freshwater fish, including grass carp Ctenopharyngodon idellus), grey mullet (Mugil cephalus) and tilapia (Oreochromis

104 sp.).

\section{Bird capturing and tracking data collection}

107 From January-December 2018, we captured nine individuals of little egret (Egretta garzetta) using clap nets ( $1.5 \mathrm{~m}$ and $2 \mathrm{~m}$ in diameter) with fish bait. We put each individual into a covered, large laundry hamper. They are soft enough for the birds from getting hurt, but strong enough for 
109 retaining the birds. We attached to each bird a solar-charged GPS-UHF logger [model PICA (5.5

$110 \mathrm{~g}$ in weight) or HARRIER (12 g), Ecotone Telemetry, Poland]), using Teflon tape and a

111 backpack harness. The captured birds weighed 290-495 g. The weight of the loggers and

112 harnesses were $<3 \%$ of the birds' weights. All birds were released within two hours at the site of

113 capture. We programmed the loggers to record data (location and speed) hourly from 5 to $7 \mathrm{pm}$

114 local time, thus tracking movements from around sunrise (before the egrets leave their roosting

115 sites) to after sunset (when they return to roost). Data were automatically stored on the loggers,

116 and were remotely downloaded every two weeks using a hand-held base station with

117 unidirectional antenna. We included data collected between 30 Jan 2018 and 22 Mar 2019 in the

118 analysis. All procedures were approved by the Agricultural Fisheries and Conservation

119 Department of the Hong Kong Government [permit number: (43) AF GR CON 09/51 Pt. 6, (99)

120 AF GR CON 09/51 Pt. 6, (166) AF GR CON 09/51 Pt. 6, (79) AF GR CON 09/51 Pt. 7].

121

122 Habitat availability

123 To determine habitat availability in the study area, we first mapped the study area using QGIS

124 3.6.1 (QGIS Development Team 2016). Next, we delineated and classified the area into six

125 habitat types using Google Earth: commercial fishponds, gei wais (tidal shrimp ponds),

126 mangroves, intertidal mudflat, drainage channels and human settlement. Subsequently, we

127 conducted fieldwork to ground-truth the habitat type. Further, we collected the draining

128 schedules of 591 commerical fishponds by interviewing their owners throughout the study

129 period, which covers $81.5 \%$ of all commercial fishponds in the entire Deep Bay area.

130

131 Data analysis

132 We performed all statistical analyses in R (R Core Team 2019), using the packages 'BBMM' and

133 'adehabitatHR' for home range analysis (Calenge 2011; Nielson et al. 2013); 'adehabitatHS' for

134 habitat selection analysis (Calenge 2011); 'lme4' for model fitting (Bates et al. 2014) and

135 'ggplot2' for graphic production (Wickham 2016).

136

137 We applied three methods to calculate the home range of individuals. First, given that the

138 location was recorded regularly each hour, we used the Brownian bridge movement model

139 (BBMM) to report the 50\% and 95\% home range as the core area and overall home range,

140 respectively (Fischer et al. 2013). Based on our preliminary field testing, we set 20 meters as the

141 location errors for BBMM. We also calculated home range using fixed kernel density estimation

142 (50\% and 95\% kernel) (Worton 1989) and minimum convex polygon (MCP) (Mohr 1947). For

143 kernel, we used the $\mathrm{h}_{\text {ref }}$ kernel density estimators (Calenge 2011). 
145 To determine if little egrets exhibit habitat preference, we used compositional analysis, which

146 compares the point habitat occurrence data with habitat availability across the entire home range

147 of each individual (Aebischer et al. 1993). We defined the 100\% minimum convex polygon

148 (MCP) of each individual as their maximum home range, and then calculated the proportion of

149 each habitat type as the habitat availability (Whisson et al. 2015). We then assigned their

150 relocations to the corresponding habitat and calculated the proportion of used habitat. Second,

151 we performed Wilk's Lambda statistic to determine their overall selection of habitat. If

152 preferences were found, we used randomization tests to conduct pair-wise comparisons of

153 resource types (Aebischer et al. 1993). Consequently, we used the eigenanalysis of selection

154 ratios to examine individual variations in habitat use in different seasons (Calenge \& Dufour

155 2006).

156

157 We tested the seasonal effect on daily home ranges, daily travel distance and proportion of daily

158 occurrence in fishponds (i.e. the proportion of GPS fixes on fishponds among all habitats during

159 the daylight period) using Linear Mixed Model (LMM) and Generalized Linear Mixed Model

160 (GLMM) followed by analysis of variance (Bolker et al. 2009). For daily home range and daily

161 travel distance, LMMs were applied and fitted with Gaussian distribution. For the proportion of

162 the daily occurrence in fishponds, we constructed GLMMs fitted with binomial distribution and

163 log-linked function. We could only collect data from two individuals in the summer (June to

164 August), so we excluded summer data from this analysis. We set bird identity as a random effect

165 and season as a fixed effect in the model (spring: March to May; autumn: September to

166 November; winter: December to February). Daily home range was calculated as the daily $50 \%$

167 and 95\% utilization distribution (UD) of each individual, using the fixed Kernel Density

168 Estimation (KDE) method (Seaman \& Powell 1996; Worton 1989). We calculated daily travel

169 distance by summing the travel distance between each successive location on each tracking day.

170 We excluded data collected from 351 tracking days that had missing data.

171

172 RESULTS

173 Between January 2018 and March 2019, we received 18839 GPS fixes (1296 tracking bird-days)

174 from nine individuals (Table 1). For individuals, the mean ( \pm SD) number of tracking days was

$175154 \pm 41$ and GPS fixes was $2093 \pm 567$.

176

177 The mean $( \pm \mathrm{SD})$ overall home range $(95 \% \mathrm{BBMM})$ and core area $(50 \% \mathrm{BBMM})$ were $9.40 \mathrm{~km}^{2}$

$178 \pm 7.68($ range $=0.85-20.62)$ and $1.31 \mathrm{~km}^{2} \pm 1.26($ range $=0.14-3.70)$, respectively $($ Table 1 ; Fig.

179 1). The length of the entire tracking duration of each individual did not correlate with the home

180 range size (Pearson's correlation; 50\% core area, $t=0.16, \mathrm{df}=7, p=0.87 ; 95 \%$ home range, $t=$ 
181

182

183

184

185

186

187

188

189

190

191

192

193

194

195

196

197

198

199

200

201

202

203

204

205

206

207

208

209

210

211

212

213

214

215

216

$0.48, \mathrm{df}=7, p=0.65)$.

The home range of all tracked individuals was dominated by fishponds (overall home range $=$ $46.8 \%$; core area $=54.3 \%$ ), intertidal mudflats (overall home range $=11.4 \%$; core area $=12.5 \%$ ) and mangroves (overall home range $=13.8 \%$; core area $=7.6 \%$ ) (Table 2 ). These three habitat types constituted over $70 \%$ of the home ranges of all individuals.

Proportion of habitats used by tracked little egrets (excluding summer) differed from the availability (Wilk's $\lambda=0.032, p<0.05$ in all cases). Commercial fishponds were the most preferred habitats, followed by mangrove, gei wais, channel and intertidal mudflat, in preferential order (Table 3). Non-wetland habitats (categorized as 'Others') were the least utilized. However, the eigenanalysis of selection ratios showed individual variation in habitat preference across seasons (Fig. 2). The first two axes explained 87.0\% (spring), 100\% (summer), $87.6 \%$ (autumn) and $86.9 \%$ (winter) of the information. Seven of the nine individuals preferred fishponds across all seasons (Fig. 2).

With data from summer excluded, the size of daily $50 \%$ home ranges $(F=67.5$, df $=2, p<$ $0.001)$, daily $95 \%$ home ranges $(F=73.8, \mathrm{df}=2, p<0.001)$, daily travel distance $(F=85.0, \mathrm{df}=$ $2, p<0.001)$, and the proportion of daily occurrence in fishponds $(F=43.2, \mathrm{df}=2, p<0.001)$ differed between seasons (Fig. 3, Table 4, Table S1). During winter, little egrets displayed the greatest movement, with largest home range and longest traveling distance; they also visited fishponds more often. The activities declined in spring and reached minimum levels in autumn.

\section{DISCUSSION}

In this study, we examined the spatial ecology of little egrets in the Inner Deep Bay, a complex landscape with a variety of wetlands and urban settlements. We found that little egrets rarely utilized non-wetland habitats $(0.1 \%$ of all point locations, Table 2$)$, indicating the species is a wetland specialist in the area. We found that little egrets selected habitats nonrandomly and preferred fishponds, and they displayed seasonal differences in movement and habitat use.

\section{Preference of fishponds}

The preference of the little egret for commercial fishponds in the inner Deep Bay agrees with other studies on ardeids (Fidorra et al. 2016). The preference of commercial fishponds is probably associated with the draining practices that enhance food availability and accessibility (Fidorra et al. 2016; Rocha et al. 2017). In our study area, the fishponds are drained for fish harvesting, between October and May (Fig. 4). In drained fishponds, a high density of prey (e.g. 
217 fish and invertebrates) become accessible to birds in shallow water (Young 1998). Our data

218 showed that most little egrets rely on fishponds as the major foraging habitat from autumn to

219 spring. Other wetland birds that likely have preference for fishponds, such as the endangered

220 black-faced spoonbill (Platalea minor), are often seen feeding alongside little egrets in fishponds

221 (Yu \& Swennen 2004). In light of the high development pressure on fishponds, our findings

222 reinforce the importance of preserving commercial fishponds in the Inner Deep Bay for this

223 group of birds.

224

225

226

227

228

229

230

231

232

233

234

235

236

237

238

239

\section{Importance of other wetlands}

Despite an obvious preference of commercial fishponds, our data indicate that other wetland types are also important to little egrets as breeding and foraging habitats ( $>41 \%$ of point locations in other wetland types, Table 2). In Hong Kong, little egrets mainly nest in mangrove, coastal shrubs and trees (Wong et al. 1999). One individual (PIC09) shifted from using commercial fishponds in other seasons to mangroves in the summer (breeding season). Overall, the channels, gei wai, mangroves and intertidal mudflats were used considerably, as each wetland type held about $10 \%$ point locations. Thus, despite fishponds were the major habitat for feeding, other wetland types acted as an alternative feeding grounds to little egrets when there were few drained fishponds available. Although we could not directly test the impact of habitat heterogeneity on movement and habitat use, the use of variety of wetlands by individuals implies wetland heterogeneity is vital to little egrets. Similar studies on other waterbird species would help us understand the impact of habitat heterogeneity on waterbird diversity, in turn informing land managers and governments how to best integrate biodiversity conservation into sustainable development plans.

240

241

Moreover, we detected individual variation in habitat use. One individual (PIC07) had distinctive habitat use, preferring a channel over other wetlands (including commercial fishponds) across all seasons (Fig. 2). In the channel that this individual frequented (located at Nam Sang Wai), an ecological-friendly design was implemented, including an unlined earth bottom and mangrove plantation, which has attracted a high number of ardeids and ducks (Lai et al. 2007). Overall, our findings also suggest that the coexistence of different wetlands is crucial for accommodating the diversity of individuals and their needs across seasons.

248

\section{Seasonal variation in habitat use and movement}

250

We detected significant seasonal differences in habitat use and movement in autumn, winter and spring. Since data were only collected from two individuals in the summer, we were unable to include this period in our analysis. According to our expectation, we found draining schedule of 
253 commercial fishponds to influence birds' spatial ecology. The largest home range, greatest

254 movements and highest occurrence in commercial fishponds occurred in winter. We suggest this

255 seasonal pattern to be due to the plentiful, but unpredictable and transient nature of food

256 availability in commercial fishponds. Winter in Hong Kong (December to February) coincides

257 with core of the drainage schedule of commercial fishponds (October to May). Drained

258 commercial fishponds are likely preferred because they contain a large amount of accessible

259 prey. However, food resources in drained fishponds are usually exhausted in a few days (Rocha

260 et al. 2017). Searching for resource-rich drained fishponds is probably frequent, but

261 unpredictable (based on fish farmer's preference), which may explain the greatest movements

262 and highest occurrence in commercial fishponds during winter. Conversely, food resources in

263 natural wetlands are likely more predictable.

264

265

266

The monthly cumulative area of fishponds drained in spring in the study period was found comparable to that in winter (Fig. 4), yet we found lower proportion of daily occurrences in

267 fishpond in spring than in winter (Fig. 3), which deviates from our expectation. This hints that

268 movement and habitat use of little egrets are shaped by a balance between foraging and

269 reproduction constraints. In Hong Kong, the reproductive season of little egrets starts in March

270 and April (Carey et al. 2001). When they begin sitting on nests and rearing youngs in mangrove,

271 foraging time and movements get limited (Maccarone \& Brzorad 2005), and hence they may not

272 be able to search for and feed in drained fishponds. Tracking more little egrets in summer and

273 areas without fishponds will help elucidate the factors influencing the temporal changes in their

274 habitat use and movement.

275

\section{CONCLUSION}

277 Besides improving our understanding of the spatial ecology of little egrets, our results reiterate

278

279

280

281

282

283

284

285

286

287

the importance of preserving wetlands, particularly commercial fishponds, in the Inner Deep Bay in Hong Kong. Human-influenced wetlands can provide not only suitable but preferable habitats for wildlife. Further, the coexistence of different types of wetlands, natural and humaninfluenced, is important in increasing habitat heterogeneity and providing alternative foraging and breeding habitats for little egrets and other waterbird species. In light of the high development pressure on wetlands in Hong Kong, we hope this study to become a springboard for similar studies to inform us how to better integrate biodiversity conservation into sustainable development plans.

\section{ACKNOWLEDGETMENTS}

Peer] reviewing PDF | (2020:03:47296:3:0:NEW 13 Aug 2020) 
288 This study was funded by the Environment and Conservation Fund of the Government of the 289 Hong Kong SAR, China (EP86/19/271). We thank the Agriculture, Fisheries and Conservation 290 Department of the Government of the Hong Kong SAR, China for project support and providing 291 permission of egret trapping and handling [(43) AF GR CON 09/51 Pt. 6, (99) AF GR CON 292 09/51 Pt. 6, (166) AF GR CON 09/51 Pt. 6, (79) AF GR CON 09/51 Pt. 7]; Dr. Xianji Wen and 293 the staff of World Wild Fund of Hong Kong in assisting field arrangement at Mai Po Nature 294 Reserve; Fion Au and Alex Chan for field assistance; and many fishpond owners for allowing 295 field work in their ponds. We acknowledge the staff of Ecotone Telemetry, particularly A. 296 Grochowska, A. Komoszyńska and L. Iliszko for their technical support on GPS tracking. We 297 are grateful to the anonymous reviewers for their careful reading of our manuscript and their 298 many insightful comments and suggestions. We thank Jonathan Fong, Sze-wing Yiu, Amy Fok, 299 Julia Leung and Henry Lee for comments on the manuscript.

300

301

302

303

304

305

306

307

308

309

310

311

312

313

314

315

316

317

318

319

320

321

322

323

\section{REFERENCES}

Aebischer NJ, Robertson PA, and Kenward RE. 1993. Compositional analysis of habitat use from animal radio-tracking data. Ecology 74:1313-1325.

Bates D, Maechler M, Bolker B, and Walker SW. 2014. lme4: Linear mixed-effects models using Eigen and S4. R package version 1.1-7. Available at http://cran.rproject.org/package $=$ lme4 (accessed 12 Mar 2017).

Bellio MG, Kingsford RT, and Kotagama SW. 2009. Natural versus artificial- wetlands and their waterbirds in Sri Lanka. Biological Conservation 142:3076-3085.

Bolker BM, Brooks ME, Clark CJ, Geange SW, Poulsen JR, Stevens MHH, and White J-SS. 2009. Generalized linear mixed models: a practical guide for ecology and evolution. Trends in Ecology \& Evolution 24:127-135.

Calenge C, and Dufour AB. 2006. Eigenanalysis of selection ratios from animal radio-tracking data. Ecology 87:2349-2355.

Calenge C. 2011. Exploratory analysis of the habitat selection by the wildlife in R: the adehabitatHS package. Available at https://trac.faunalia.it/animove/ (accessed 13 Dec 2019).

Carey GJ, Chalmers ML, Diskin DA, Leader PJ, Leven MR, Lewthwaite MR, Melville DS, Turnbull M, and Young L. 2001. The avifauna of Hong Kong. Hong Kong: Hong Kong Bird Watching Society.

Davidson NC. 2014. How much wetland has the world lost? Long-term and recent trends in global wetland area. Marine and Freshwater Research 65:934-941.

El-Hacen E-HM, Overdijk O, Lok T, Olff H, and Piersma T. 2013. Home range, habitat selection, and foraging rhythm in Mauritanian Spoonbills (Platalea leucorodia balsaci): a 
324

325

326

327

328

329

330

331

332

333

334

335

336

337

338

339

340

341

342

343

344

345

346

347

348

349

350

351

352

353

354

355

356

357

358

359

satellite tracking study. Waterbirds 36:277-286.

Fidorra JC, Frederick PC, Evers DC, and Meyer KD. 2016. Selection of human-influenced and natural wetlands by great egrets at multiple scales in the southeastern USA. The Condor 118:46-56.

Fischer JW, Walter WD, and Avery ML. 2013. Brownian bridge movement models to characterize birds' home ranges. The Condor 115:298-305.

Giosa E, Mammides C, and Zotos S. 2018. The importance of artificial wetlands for birds: A case study from Cyprus. PloS one 13:e0197286.

Gong P, Niu Z, Cheng X, Zhao K, Zhou D, Guo J, Liang L, Wang X, Li D, Huang H, Wang Y, Wang K, Li W, Wang X, Ying Q, Yang Z, Ye Y, Li Z, Zhuang D, Chi Y, Zhou H, and Yan J. 2010. China's wetland change (1990-2000) determined by remote sensing. Science China Earth Sciences 53:1036-1042.

Hong Kong Bird Watching Society. 2018. Mai Po Inner Deep Bay Ramsar Site waterbird monitoring programme 2017-18. Report by the Hong Kong Bird Watching Society to the Agriculture, Fisheries and Conservation Department, Hong Kong SAR Government. Available at http://www.hkbws.org.hk/web/chi/documents/report/summer_report_2017.pdf(accessed 1 March 2020).

Kloskowski J, Green AJ, Polak M, Bustamante J, and Krogulec J. 2009. Complementary use of natural and artificial wetlands by waterbirds wintering in Doñana, south-west Spain. Aquatic Conservation: Marine and Freshwater Ecosystems 19:815-826.

Koczur LM, Kent GM, Ballard BM, Meyer KD, and Green MC. 2018. Space use and movements of adult reddish egrets (Egretta rufescens) during winter. Waterbirds 41:115.

Lai PCC, Lee WH, and Wong BSF. 2007. Construction of a drainage channel at Inner Deep Bay, Hong Kong: mitigating ecological and landscape impact through an environmentally friendly design. Landscape and Ecological Engineering 3:179-185.

Li D, Chen S, Lloyd H, Zhu S, Shan K, and Zhang Z. 2013. The importance of artificial habitats to migratory waterbirds within a natural/artificial wetland mosaic, Yellow River Delta, China. Bird Conservation International 23:184-198.

Ma Z, Li B, Zhao B, Jing K, Tang S, and Chen J. 2004. Are artificial wetlands good alternatives to natural wetlands for waterbirds? - A case study on Chongming Island, China. Biodiversity and Conservation 13:333-350.

Maccarone AD, and Brzorad JN. 2005. Foraging microhabitat selection by wading birds in a tidal estuary, with implications for conservation. Waterbirds 28:383-391.

Márquez-Ferrando R, Figuerola J, Hooijmeijer JCEW, and Piersma T. 2014. Recently created 
360

361

362

363

364

365

366

367

368

369

370

371

372

373

374

375

376

377

378

379

380

381

382

383

384

385

386

387

388

389

390

391

392

393

394

395

man-made habitats in Doñana provide alternative wintering space for the threatened Continental European black-tailed godwit population. Biological Conservation 171:127135.

Martínez-Vilalta A, Motis A, Christie DA, and Kirwan GM. 2019. Little Egret (Egretta garzetta). In: del Hoyo J, Elliott A, Sargatal J, Christie DA, and de Juana E, eds. Handbook of the Birds of the World Alive. Barcelona, Spain: Lynx Edicions.

Mitchell C, Griffin L, Maciver A, Minshull B, and Makan N. 2016. Use of GPS tags to describe the home ranges, migration routes, stop-over locations and breeding area of Taiga Bean Geese Anser fabalis fabalis wintering in central Scotland. Bird study 63:437-446.

Mohr CO. 1947. Table of equivalent populations of North American small mammals. The American Midland Naturalist 37:223-249.

Morton B. 2016. Hong Kong's mangrove biodiversity and its conservation within the context of a southern Chinese megalopolis. A review and a proposal for Lai Chi Wo to be designated as a World Heritage Site. Regional studies in marine science 8:382-399.

Murillo-Pacheco J, López-Iborra GM, Escobar F, Bonilla-Rojas WF, and Verdú JR. 2018. The value of small, natural and man-made wetlands for bird diversity in the east Colombian Piedmont. Aquatic Conservation: Marine and Freshwater Ecosystems 28:87-97.

Navedo JG, Fernandez G, Fonseca J, and Drever MC. 2015. A potential role of shrimp farms for the conservation of Nearctic shorebird populations. Estuaries and Coasts 38:836-845.

Nielson R, Sawyer H, and McDonald T. 2013. BBMM: Brownian bridge movement model. R package version 3.0 .

QGIS Development Team. 2016. QGIS Geographic Information System. Open Source Geospatial Foundation Project. Available at http://qgis.osgeo.org.

Ramirez F, Navarro J, Afan I, Hobson KA, Delgado A, and Forero MG. 2012. Adapting to a changing world: unraveling the role of man-made habitats as alternative feeding areas for slender-billed gull (Chroicocephalus genei). PloS one 7:e47551.

R Core Team. 2019. R: A language and environment for statistical computing. $\mathrm{R}$ foundation for statistical computing, Vienna, Austria. Available at https://www.R-project.org/ (accessed 21 October 2017).

Ren H, Wu X, Ning T, Huang G, Wang J, Jian S, and Lu H. 2010. Wetland changes and mangrove restoration planning in Shenzhen Bay, Southern China. Landscape and Ecological Engineering 7:241-250.

Rocha AR, Ramos JA, Paredes T, and Masero JA. 2017. Coastal saltpans as foraging grounds for migrating shorebirds: an experimentally drained fish pond in Portugal. Hydrobiologia 790:141-155.

Seaman DE, and Powell RA. 1996. An evaluation of the accuracy of kernel density estimators 
396 for home range analysis. Ecology 77:2075-2085.

397 Sebastián-González E, and Green AJ. 2016. Reduction of avian diversity in created versus 398 natural and restored wetlands. Ecography 39:1176-1184.

399 Takano LL, and Haig SM. 2004. Seasonal movement and home range of the Mariana common 400 moorhen. The Condor 106:652-663.

401 Whisson DA, Weston MA, and Shannon K. 2015. Home range, habitat use and movements by 402 the little raven (Corvus mellori) in a coastal peri-urban landscape. Wildlife Research $403 \quad 42: 500-508$.

404 Wickham H. 2016. ggplot2: elegant graphics for data analysis. New York: Springer.

405 Wong LC, Corlett RT, Young L, and Lee JSY. 1999. Foraging flights of nesting egrets and 406 herons at a Hong Kong egretry, south China. Waterbirds 22:424-434.

407 Worton BJ. 1989. Kernel methods for estimating the utilization distribution in home-range 408 studies. Ecology 70:164-168.

409 Young L. 1998. The importance to ardeids of the Deep Bay fish ponds, Hong Kong. Biological $410 \quad$ Conservation 84:293-300.

411 Yu YT, and Swennen C. 2004. Habitat use of the Black-faced Spoonbill. Waterbirds 27:129412 134.

413 
Figure 1

$50 \%$ core areas and $95 \%$ overall home ranges of nine little egrets in the Inner Deep Bay, Hong Kong, using Brownian bridge movement model.

A) CHIO1, B) HUNO1, C) HUNO2, D) HUNO3, E) HUN04, F) PIC05, G) PIC06, H) PIC07, I) PIC09. 


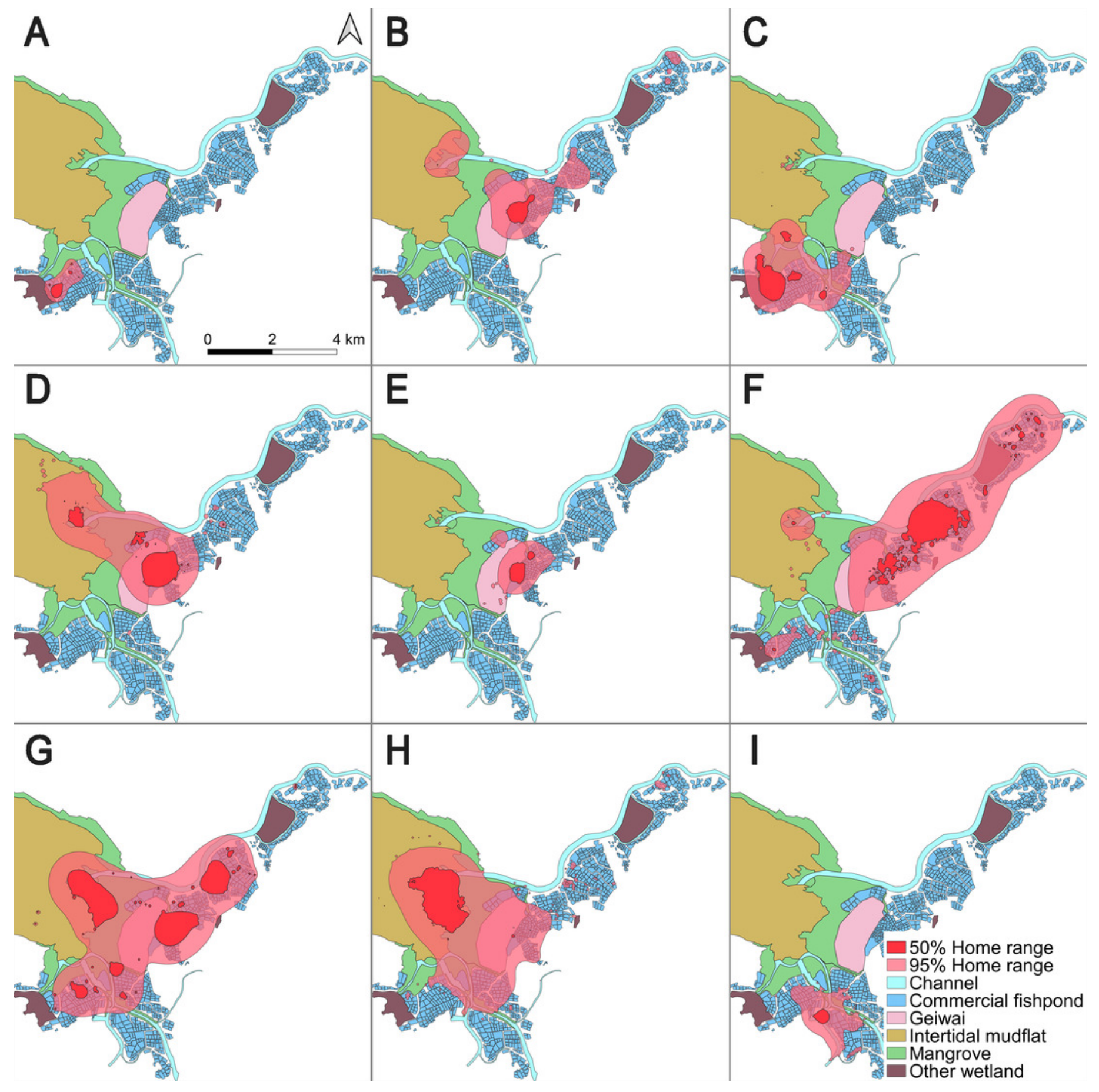


Figure 2

Eigen analyses of selection ratios of habitat selection of nine little egrets in six habitat types in different seasons.

Habitat types loadings on the first two factorial axes and individual scores on the first factorial plant were displayed by seasons. A-B, Spring; C-D, Summer; E-F, Autumn; G-H, Winter. The numbers correspond to the animals. 1, CHI01; 2, HUN01; 3, HUN02; 4, HUN03; 5, HUN04; 6, PIC05; 7, PIC06; 8, PIC07; 9, PIC09. 


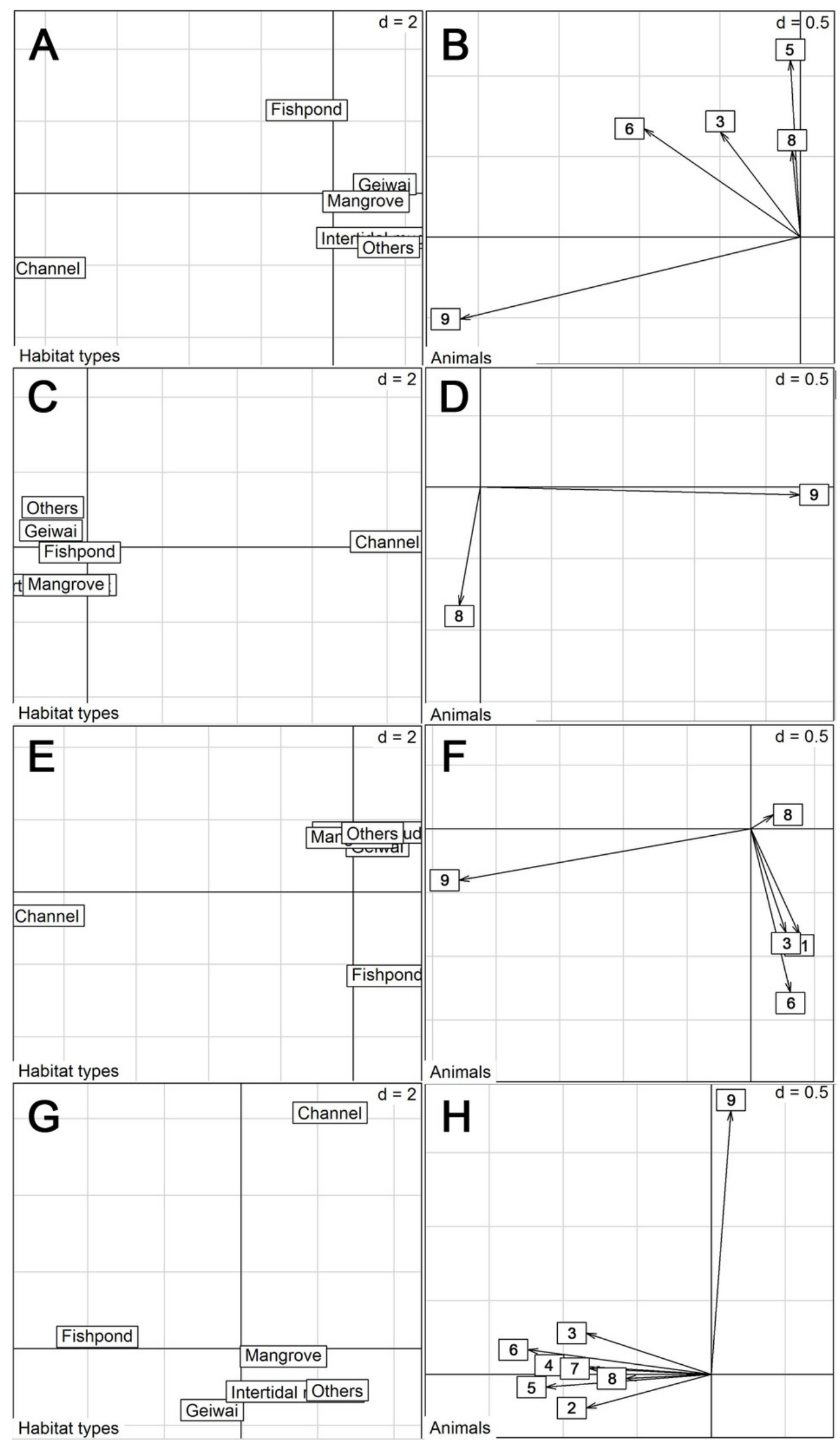

Peer) reviewing PDF | (2020:03:47296:3:0:NEW 13 Aug 2020) 
Figure 3

The grand mean and standard error of the activities of nine little egrets.

(A) 50\% home range, (B) 95\% home range, (C) daily travel distances and (D) proportion of daily occurrence in fishponds. Data collected in summer was only visualized but excluded in the analysis due to limited sample size.

A

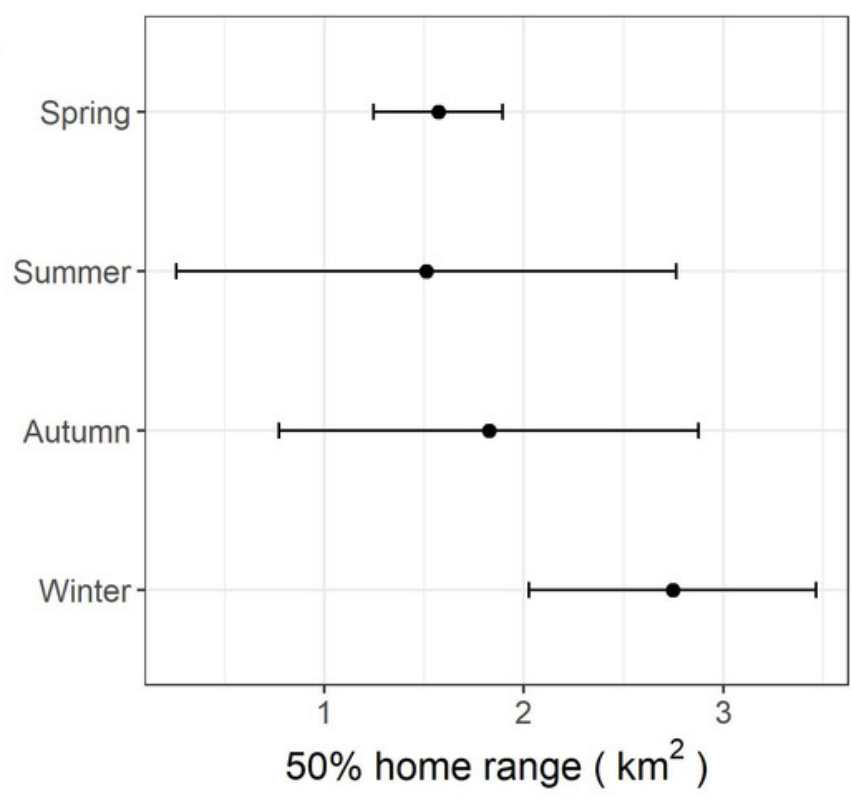

C

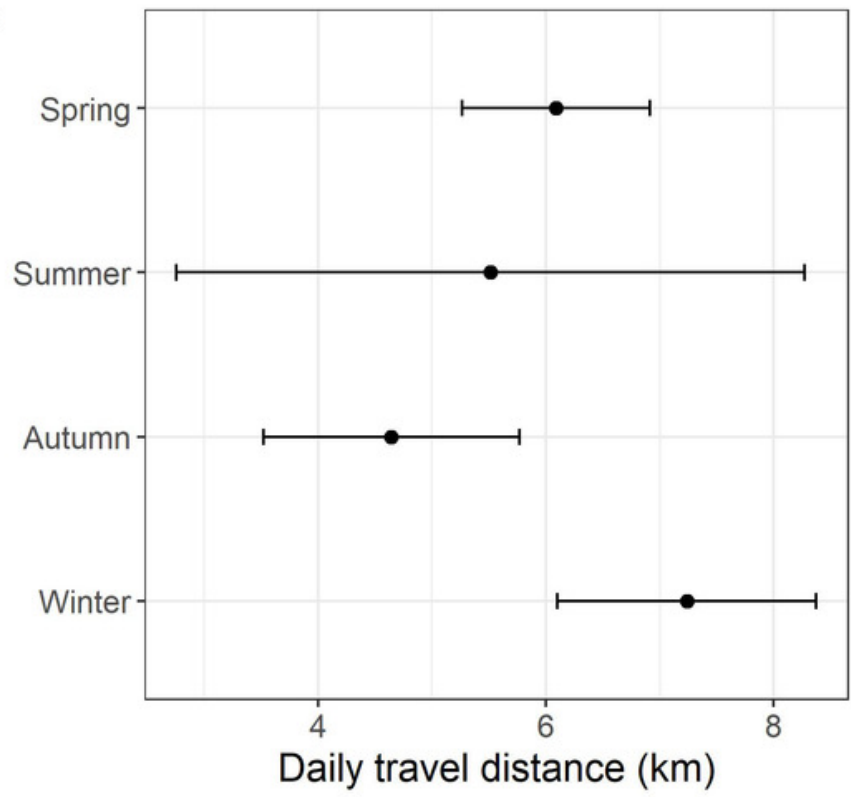

B

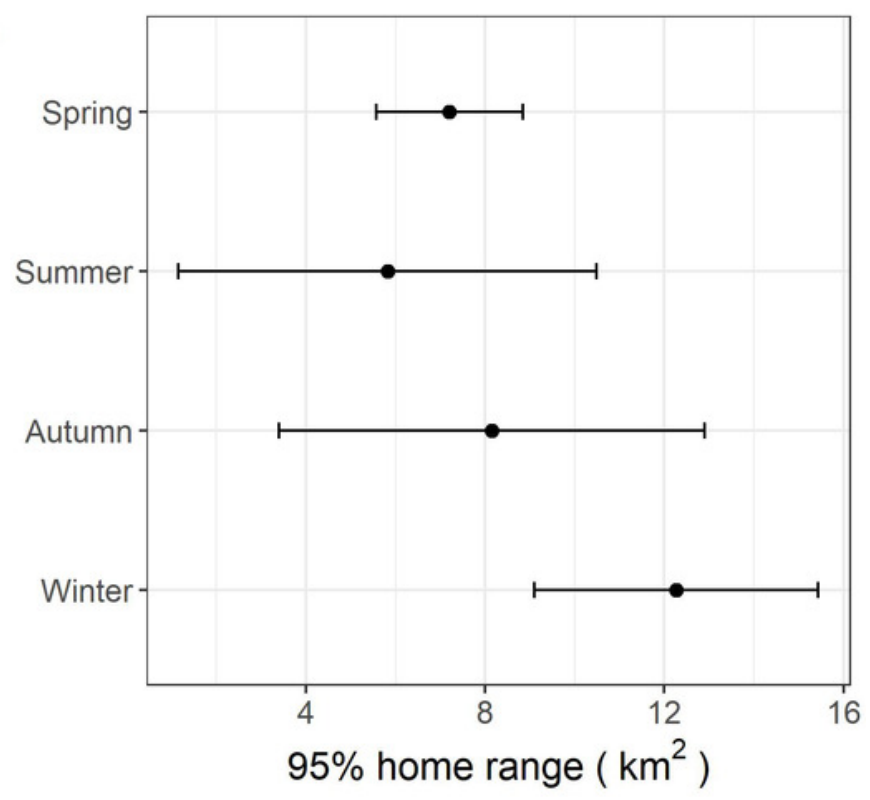

D

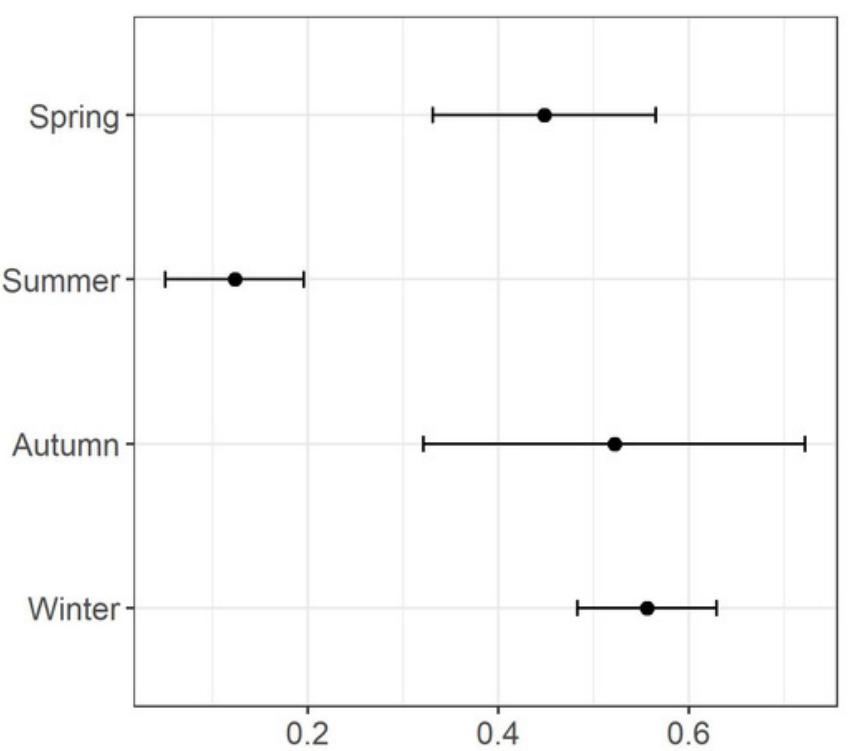

Proportion of daily occurrence in fishponds 
Figure 4

Monthly cumulative area (and standard errors) of commercial fishponds that were drained according to season in the Inner Deep Bay, Hong Kong in 2018-2019.

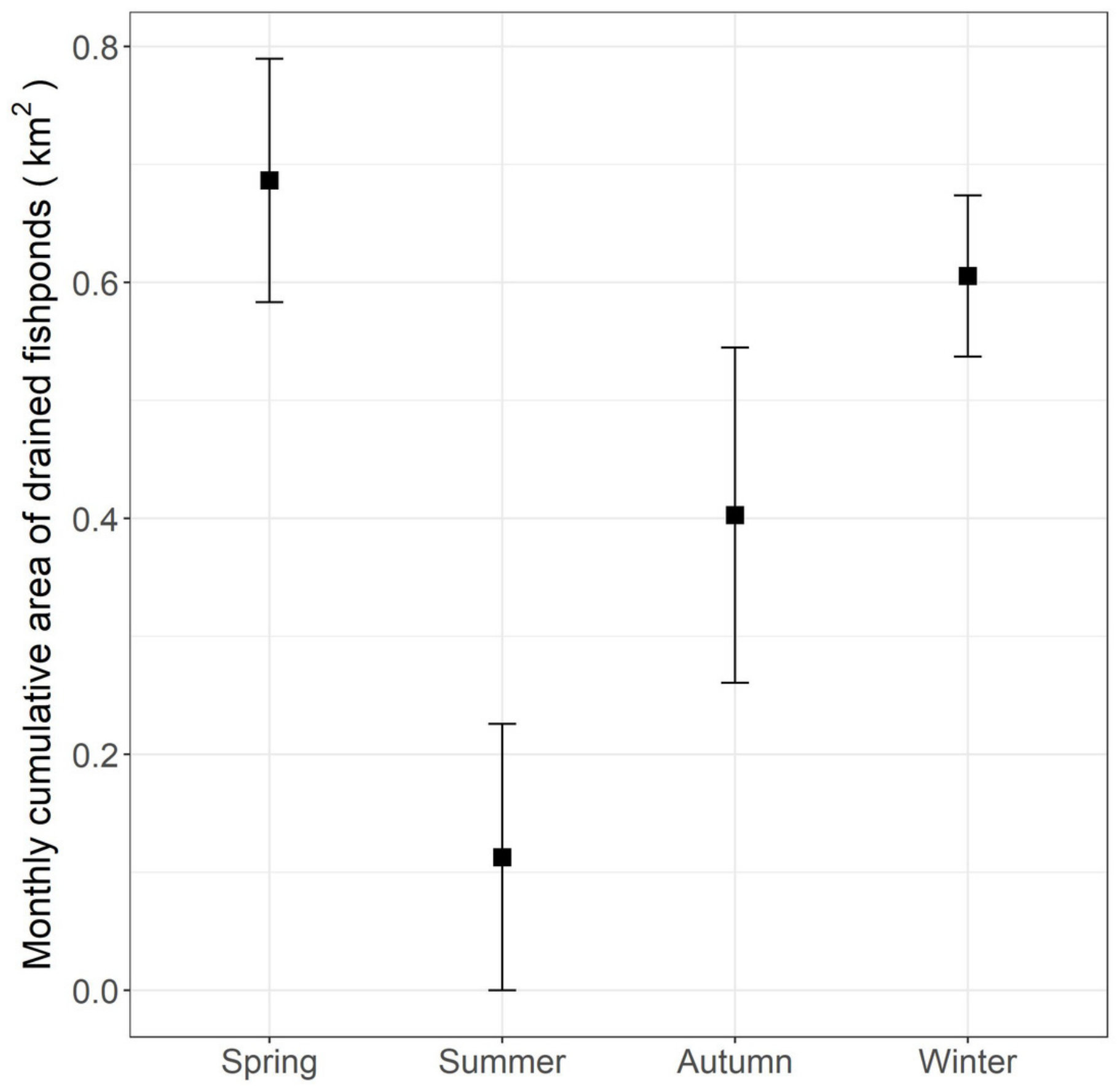




\section{Table 1 (on next page)}

Home range of little egrets in the inner Deep Bay area, Hong Kong. 
1 Table 1. Home range of little egrets in the Inner Deep Bay, Hong Kong.

\begin{tabular}{|c|c|c|c|c|c|c|c|c|c|}
\hline \multirow[t]{4}{*}{ ID } & \multirow{4}{*}{$\begin{array}{l}\text { Tracker } \\
\text { model }\end{array}$} & \multirow{4}{*}{$\begin{array}{l}\text { Start date } \\
\text { of } \\
\text { tracking }\end{array}$} & \multirow{4}{*}{$\begin{array}{l}\text { Last } \\
\text { date of } \\
\text { signal } \\
\text { received }\end{array}$} & \multirow{4}{*}{$\begin{array}{c}\text { Tracking } \\
\text { duration } \\
\text { (day) }\end{array}$} & \multicolumn{5}{|c|}{ Home range $\left(\mathrm{km}^{2}\right)$} \\
\hline & & & & & $100 \%$ & $50 \%$ & $95 \%$ & $50 \%$ & $95 \%$ \\
\hline & & & & & MCP & Kernal & Kernal & BBMM & BBMM \\
\hline & & & & & & & & & \\
\hline CHI01 & PICA & $28 / 09 / 18$ & $15 / 11 / 18$ & 49 & 1.54 & 0.13 & 0.79 & 0.14 & 0.85 \\
\hline HUN01 & HARRIER & $01 / 12 / 18$ & $08 / 02 / 19$ & 70 & 26.11 & 0.76 & 7.95 & 0.40 & 5.85 \\
\hline HUN02 & HARRIER & $18 / 10 / 18$ & $22 / 03 / 19$ & 156 & 12.97 & 1.03 & 5.73 & 0.97 & 6.33 \\
\hline HUN03 & HARRIER & $01 / 12 / 18$ & $14 / 02 / 19$ & 76 & 16.16 & 1.53 & 10.28 & 1.37 & 10.17 \\
\hline HUN04 & HARRIER & $01 / 12 / 18$ & $22 / 03 / 19$ & 112 & 17.52 & 0.33 & 1.30 & 0.30 & 2.25 \\
\hline PIC05 & PICA & $30 / 01 / 18$ & $08 / 02 / 19$ & $217^{*}$ & 38.38 & 3.90 & 24.61 & 2.58 & 20.05 \\
\hline PIC06 & PICA & $30 / 01 / 18$ & $28 / 02 / 18$ & 30 & 25.57 & 7.55 & 27.29 & 3.70 & 20.62 \\
\hline PIC07 & PICA & $30 / 01 / 18$ & $27 / 02 / 19$ & 394 & 41.04 & 2.03 & 15.32 & 2.20 & 15.81 \\
\hline PIC09 & PICA & $30 / 01 / 18$ & $21 / 03 / 19$ & $289 *$ & 24.72 & 0.10 & 1.62 & 0.15 & 2.68 \\
\hline
\end{tabular}

* PIC05 migrated out of Hong Kong from 13/05/18 to 05/08/18 and PIC09 migrated from 29/03/18 to $01 / 08 / 2018$. Data obtained in this period were excluded in the analysis. 


\section{Table 2 (on next page)}

Proportion (SE) of habitat types within the home ranges for the tracked little egrets, and the proportion of little egret locations within each habitat type in the Inner Deep Bay, Hong Kong. 
1 Table 2. Proportion (SE) of habitat types within the home ranges for the tracked little egrets, and

2 the proportion of little egret locations within each habitat type in the inner Deep Bay, Hong

3 Kong.

\begin{tabular}{lcccc}
\hline Habitat types & $100 \%$ MCP & $\begin{array}{c}\text { 95\% BBMM } \\
\text { home range }\end{array}$ & $\begin{array}{c}50 \% \text { BBMM } \\
\text { home range }\end{array}$ & $\begin{array}{c}\text { Point } \\
\text { locations }\end{array}$ \\
\hline Channel & $6.8(0.4)$ & $5.5(1.6)$ & $7.5(5.2)$ & $9.5(7.3)$ \\
Fishpond & $31.3(2.7)$ & $46.8(6.7)$ & $54.3(10.4)$ & $58.7(9.5)$ \\
Gei wai & $7.4(1.3)$ & $11.4(3.8)$ & $11.9(5.7)$ & $9.7(4.5)$ \\
Mangrove & $19.9(2.5)$ & $13.8(2.5)$ & $7.6(2.6)$ & $11.9(3.4)$ \\
Intertidal mudflat & $14.0(2.6)$ & $11.4(4.3)$ & $12.5(8.3)$ & $10.2(5.2)$ \\
Others & $20.5(3.9)$ & $11.1(3.6)$ & $6.2(2.7)$ & $0.1(0.0)$ \\
\hline
\end{tabular}

4

5 


\section{Table 3 (on next page)}

The ranking matrix for habitat selection of the nine little egrets. The matrix compares the proportion of used habitat based on the relocations and 100\% MCP (available habitat).

+ , preference, -, avoidance, a triple sign indicates significant deviation from random at $\mathrm{p}<$ 0.05. The ranking list ranges from 0 (most avoided) to 5 (most selected). 
1 Table 3. The ranking matrix for habitat selection of the nine little egrets. The matrix compares

2 the proportion of used habitat based on the relocations and 100\% MCP (available habitat); +,

3 preference, -, avoidance, a triple sign indicates significant deviation from random at $\mathrm{p}<0.05$.

4 The ranking list ranges from 0 (most avoided) to 5 (most selected).

\begin{tabular}{lccccccc}
\hline & Fishpond & Mangrove & Gei wai & Channel & $\begin{array}{c}\text { Intertidal } \\
\text { mudflat }\end{array}$ & Others & Rank \\
& & & & & & \\
\hline Fishpond & & +++ & +++ & +++ & +++ & +++ & 5 \\
Mangrove & --- & & + & + & + & +++ & 4 \\
Gei wai & --- & - & & + & + & +++ & 3 \\
Channel & --- & - & - & & + & +++ & 2 \\
Intertidal mudflat & --- & - & - & - & & +++ & 1 \\
Others & --- & --- & --- & --- & --- & & 0 \\
\hline
\end{tabular}

5 


\section{Table 4 (on next page)}

Statistical summary of the regression models for the effects of season on the activities of little egrets. Summer was excluded in the analysis due to limited sample size. 
1 Table 4. Statistical summary of the regression models for the effects of season on the activities of

2 little egrets. Summer was excluded in the analysis due to limited sample sizes.

\begin{tabular}{lcrrrrr}
\hline $\begin{array}{l}\text { Source of } \\
\text { variation }\end{array}$ & Model & Season & Estimate & SE & $\mathrm{t}$ & $p$ \\
\hline Log daily 50\% & LMM & Spring & -0.189 & 0.399 & -0.47 & 0.65 \\
home range & & Autumn & -1.145 & 0.393 & -2.92 & $<0.05$ \\
& & Winter & 0.079 & 0.387 & 0.08 & 0.84 \\
Log daily 95\% & LMM & Spring & 1.354 & 0.395 & 3.43 & $<0.01$ \\
home range & & Autumn & 0.345 & 0.388 & 0.89 & 0.40 \\
& & Winter & 1.620 & 0.383 & 4.23 & $<0.01$ \\
Log daily travel & LMM & Spring & 1.637 & 0.163 & 10.0 & $<0.01$ \\
distance & & Autumn & 1.154 & 0.160 & 7.21 & $<0.01$ \\
& & Winter & 1.750 & 0.158 & 11.1 & $<0.01$ \\
Occurrence & \multirow{2}{*}{ GLMM } & Spring & 0.494 & 0.096 & 5.17 & $<0.01$ \\
frequency in & & Autumn & 0.459 & 0.095 & 4.84 & $<0.01$ \\
fishponds & & Winter & 0.621 & 0.094 & 6.60 & $<0.01$ \\
\hline
\end{tabular}

3 